\title{
Estimated Gestational Age
}

National Cancer Institute

\section{Source}

National Cancer Institute. Estimated Gestational Age. NCI Thesaurus. Code C122188.

An approximate calculation of the gestational age of the fetus. 